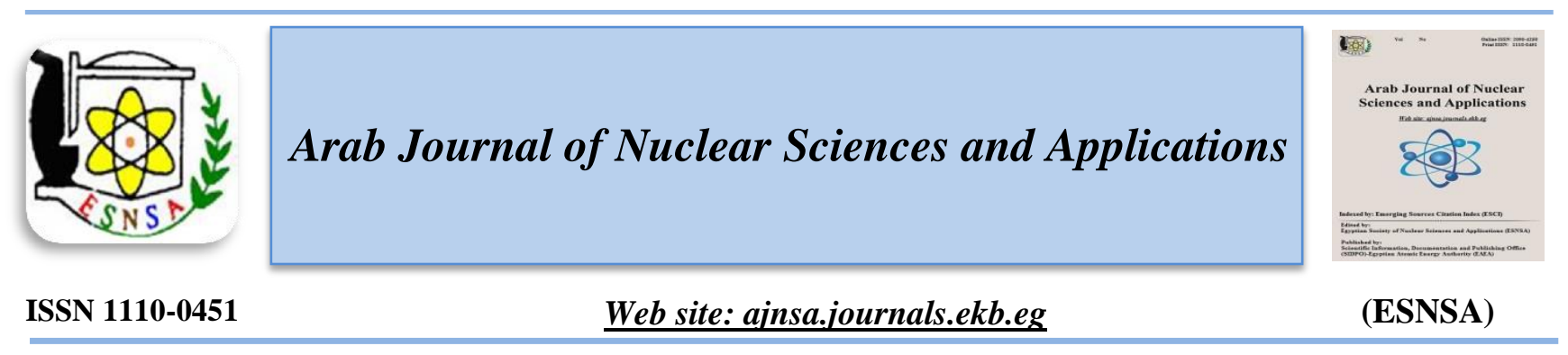

\title{
The Induced Changes in the Bulk Etch Rate and the Thermal Stability of PADC by the Effect of Long Storing Time at Room Temperature and Heat Treatment
}

\author{
S.M. Mokhtar ${ }^{(1)}$ M.Y.Shoeib ${ }^{(2)}$ \\ ${ }^{1}$ Department of Chemistry, Women's College, Ain Shams University, Cairo, Egypt \\ ${ }^{2}$ Basic Science Department (Physics), Modern Academy for Engineering \& Technology in Maadi, Cairo, Egypt
}

Received $14^{\text {th }}$ Feb. 2018 Accepted $4^{\text {th }}$ June 2018

\begin{abstract}
The samples of poly allyl diglycol carbonate PADC (CR-39) (stored and fresh samples) polymer track detectors have been heated at different annealing temperatures and different annealing times. The thermal stability has been studied for different annealed samples; it was also examined as a function of the storage time. The percentage degree of crystallinity has been studied for different annealed samples and stored samples. The samples were etched in $6 \mathrm{M} \mathrm{KOH}$ solution at $70^{\circ} \mathrm{C}$ for $3 \mathrm{~h}$. The variation of bulk etch rate of isochronal annealed samples has been studied. The results indicate an improvement in the thermal stability of Poly allyl diglycol carbonate PADC; where the bulk etch rate increases with the increase in the annealing temperature and annealing time. The storage time has no noticeable effect on the bulk etch rate of un- annealed samples, though the thermal stability of PADC improved with increasing the storage time.
\end{abstract}

Keywords: CR-39, Annealing temperature, Storage time, Thermal stability, Activation energy

\section{Introduction}

Nuclear Track Detectors (NTDs) are employed in several scientific and technological applications [1]. Pollyallyl diglycol carbonate (PADC), known as CR-39, is a detector in forms of transparent, colorless, inflexible plastic. CR-39 is one of the Solid State Nuclear Track Detectors (SSNTDs) which consists of repetitions of the component $\left(\mathrm{C}_{12}\right.$ $\left.\begin{array}{lll}\mathrm{H}_{18} & \mathrm{O}_{7}\end{array}\right)$. It has an amorphous, cross-linked structure which is very sensitive to heavy ion damage. In addition to its general thermoset characteristics, CR-39 is a high optical plastic used in making lightweight spectacle lenses [2-4].The damage trail (called latent track) produced by an ionizing particle can be made visible with an optical microscope through a chemical etching process in aqueous solution of either $\mathrm{NaOH}$ or $\mathrm{KOH}$ at a proper concentration and temperature [5]. This process is known as chemical etching treatment (CE), so, it is fully understood that appropriate chemical reagents attack the damage zone at a higher velocity (track etch velocity, $V_{t}$ ) than that through the undamaged zone (bulk etch rate, $\left.V_{b}\right)$. During the chemical etching process, the measurement of the bulk etch rate is essential to study the detector sensitivity [6]. The bulk etch rate is usually determined from both etching duration and the radius of the etched high- LET track particles like fission fragments, which equals half the thickness removed [7]. It is important to measure the bulk etching rate $V_{b}$ for any detector material to be used because of its strong dependency on the manufacturing and environmental conditions. For example, plastics with the same basic constituents may contain different amounts of plasticizers as additives,

Corresponding author: drmarwashoeib@hotmail.com

DOI: 10.21608 /ajnsa.2018.2917.1058

(C) Scientific Information, Documentation and Publishing Office (SIDPO)-EAEA 
which significantly affect the etching characteristics [8].

Annealing is a process by which the latent damage trails produced in SSNTD by charged particles at elevated temperatures are completely or partially removed. The annealing models presume that the annealing of damage trails occurs due to diffusion of atomic defects through the crystal lattice or the movement of molecular fragments within a polymer [9,10]. At elevated temperatures, polymers undergo considerable chemical and physical changes involving reactions either with or without bond rupture of the main chain. Bond rupture takes place when the energy of thermal motion at some points of the system becomes comparable with the energy of a chemical bond. The presence of oxygen in the polymer, especially in the backbone chain, sharply increases the rate of thermal degradation [4]. The temperature range in which the ageing occurs depends on the chemical structure of the polymer and can be quite wide. Hence it is not surprising that CR-39, polymerized even at elevated temperatures, exhibits considerable ageing behavior at room temperature and below [11,12].

Apart from physical ageing, the CR-39 plastic can undergo chemical ageing, (i.e. the change of the structure and properties of the material associated with slow chemical changes). When CR-39 is polymerized, it does not reach full conversion, and some residual unsaturation is left in the plastic. This can be in the form of pendant allyl groups or relatively stable allyl radicals. It is known that free radicals immobilized in the polymer solid can survive for a considerable time at room temperature (up to several months in some cases) before reacting [13]. By the ageing of polymers, we mean the set of chemical and physical changes detracting from the mechanical properties that lower or decrease the effectiveness of polymeric articles in service. In its broader meaning, ageing can be defined as any change in the molecular, super-molecular, or phase structure of polymers and materials leading to change in the physicomechanical properties in the storage or service of the relevant articles [14].

Thermal studies are one of the most useful studies since the different thermal properties of a polymer are strongly dependent on their internal structure of the polymer [15]. Thermoplastic polymers may be subjected to high temperatures, whereas thermosetting polymers, after the completion of polymerization, can eventually lose their strength if they are exposed to high temperatures since degradation occurs in them. The most critical effect of increased temperature is an increased rate of chemical reaction which involves breaking and recombination of bonds. As a result, the properties of polymers change completely [16].

\section{Experimental Details}

Material and irradiation conditions

The samples of PADC(CR-39) polymer of average thickness 1mm, obtained from TASTRAK (manufactured and provided by Track Analysis Systems Ltd. (TASL), Bristol, UK), were cut into small pieces of $1 \times 1 \mathrm{~cm}^{2}$. The samples were classified into three categories, the first one was stored for 20 years at room temperature (around $35^{\circ} \mathrm{C}$ ) in open air, the second group was stored for 30 years at room temperature (around $35^{\circ} \mathrm{C}$ ) in open air, while the third group is a fresh sample exposed to open air to collect alpha particles.

\section{Annealing and etching process conditions}

The isothermal and isochronal annealing were carried out at 100 and $200^{\circ} \mathrm{C}$ for 1 and $8 \mathrm{~h}$ for the different samples (stored samples and fresh samples). WTC binder oven with an accuracy of $\pm 2^{\circ} \mathrm{C}$ (Inorganic and Analytical LaboratoryWomen's College Ain Shams University) was used to anneal the samples at temperatures 100and $200^{\circ} \mathrm{C}$ for 1 and 8 hours as annealing duration.

The etching process was carried out for different isochronal annealed samples (fresh and stored) with $6 \mathrm{M} \mathrm{KOH}$ as etchant solution for $3 \mathrm{~h}$ etching duration at $(70 \pm 1){ }^{\circ} \mathrm{C}$ in a water bath system.

\section{Measurements}

The bulk etch rate was determined for all samples using digital micrometer of accuracy $1 \mu \mathrm{m}$, where the thickness before and after etching process was measured with the digital micrometer.

The initial temperature at the beginning of the thermal decomposition of the polymer, the activation energy of the thermal stability and the weight loss at the final temperature of decomposition were determined for pristine and annealed samples (fresh and stored samples) using (TGA) thermo gravimetric analysis technique, where the samples' analyses were created with TGA- $50 H$ in Ain- Shams University Central Lab (ASUCL) with heating rate $20^{\circ} \mathrm{C} / \mathrm{min}$. 
X-ray diffraction has been carried out. A Philips diffractometer, model X Pert MPD (Women's College Ain Shams University), was used, where the etched sample was subjected to $\mathrm{X}$ - ray analysis under working conditions of $40 \mathrm{kV}$ and $25 \mathrm{~mA}$.

Jasco FT-IR 460 Pulse, made in Japan, with accumulation 16 , resolution $4 \mathrm{~cm}^{-1}$, auto gain and auto scanning speed $2 \mathrm{~mm} / \mathrm{s}$ (in National Research Center of Egypt), was used to determine the function of the side groups of the polymeric pristine sample and the etched sample (etched pristine sample). The spectra were recorded in the wave number range of $4000-400 \mathrm{~cm}^{-1}$.

\section{Results and Discussion}

In order to identify the effect of heat treatment and storage time at room temperature on the thermal stability and bulk etch rate $\mathrm{V}_{\mathrm{b}}(\mu \mathrm{m} / \mathrm{h})$ of different PADC (CR- 39) samples, (stored samples at the room temperature for 20 and 30 years) samples stored at room temperature for 20 and 30 years were compared with fresh samples.

The bulk etch rate was determined using thickness measurement technique from the equation [17]:

$$
\begin{aligned}
& V_{b}=\frac{\Delta L}{2 \Delta t} \\
& =\frac{L_{1}-L_{2}}{2 \Delta t}
\end{aligned}
$$

where, $\Delta L$ is the removal thickness, $L_{1}$ : is the initial thickness, $L_{2}$ : is the final thickness after etching, $\Delta t$ : is the etching time.

Figure (1) illustrates the behavior of the bulk etch rate $V_{b} \mu \mathrm{m} / \mathrm{hr}$ with storage time in years for different un-annealed samples (samples stored at room temperature), the figure clarifies the equal values of the bulk etch rate $\mathrm{V}_{\mathrm{b}}$ for new and stored PADC un-annealed samples. The results indicate that the storage time has no noticeable effect on the bulk etch rate $\mathrm{V}_{\mathrm{b}}$ of different un-annealed PADC (CR-39) samples. Table (1) shows the relation between the bulk etch rate $\mathrm{V}_{\mathrm{b}}$ and the annealing temperature ${ }^{\circ} \mathrm{C}$ at annealing times, 1 and $8 \mathrm{hr}$, respectively. The bulk etch rate $\mathrm{V}_{\mathrm{b}}$ of stored PADC (CR-39) samples for 30 years has the greatest value and the bulk etch rate $\mathrm{V}_{\mathrm{b}}$ is nearly equal for different annealed PADC (CR-39) samples (new and storage samples) at $100^{\circ} \mathrm{C}$, while the bulk etch rate $\mathrm{V}_{\mathrm{b}}$ of stored annealed samples (for 30 years) at $200^{\circ} \mathrm{C}$ has the largest value. The smallest value was recorded for the new annealed PADC (CR-39) samples. Table (2) illustrates that the bulk etch rate does not depend on the storage time for annealed samples at low temperature $\left(50^{\circ} \mathrm{C}\right)$. The bulk etch rate increases with the increase in the storage time for annealed samples at 100,150 and $200^{\circ} \mathrm{C}$. The general behavior of the bulk etch rate $\mathrm{V}_{\mathrm{b}}$ versus the annealing temperature and the annealing time agrees with the results of Abou El- Khier et al., 1995 and Pinhero Filho et al., 1996 [18-20]. The rate of increasing the bulk etch rate $\mathrm{V}_{\mathrm{b}}$ depends strongly on the annealing temperature. The Annealing process is commonly assumed to be a diffusion process in which displaced atoms are restored to their original positions under the influence of thermal energy [10]. The most critical effect of increased temperature is an increased rate of chemical reaction which involves breaking and recombination of bonds [16].

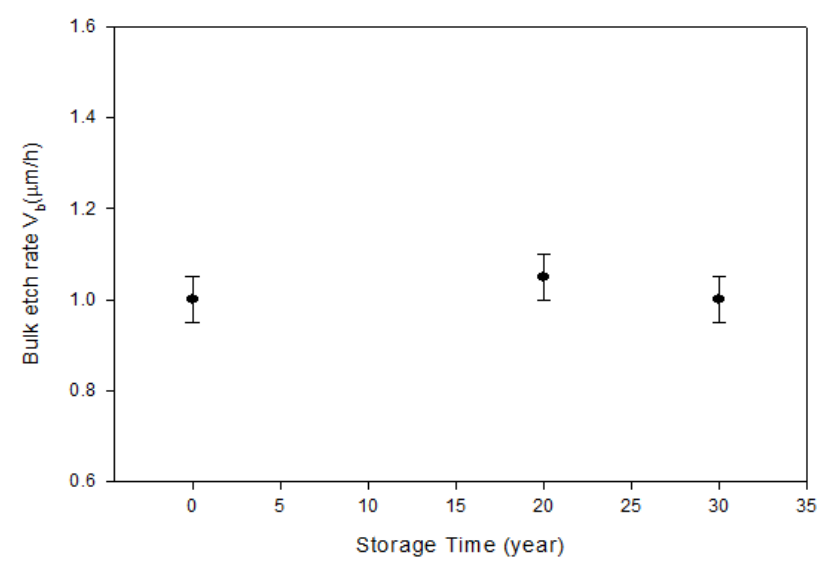

Figure (1): The relation between the bulk etch rate and the storage time for different pristine samples stored at room temperature

Thermal degradation is a very important process which clears the influence of the polymer structure on the thermal stability, the optimum temperature of operation and the activation energies associated with the degradation process. Thermogravimetric analysis, TGA, has been proved to be a relatively fast and accurate method for the determination of the kinetic parameters of the degradation process $[21,22]$. TGA thermograms of blank and isochronal annealed samples of PADC (CR-39) detector at annealing temperatures of 100 and $200^{\circ} \mathrm{C}$ for $1 \mathrm{~h}$ as an annealing duration are presented in Figure (2). Figure (2-a) shows the effect of isochronal annealing on the thermal stability of polymeric material of fresh PADC (CR-39) samples. Thermogravimetric curves of pristine and isochronal annealed samples of storedPADC (CR-39) samples for 20 and 30 years ago at room temperature are shown in Figure (2.b and c). 
Table (1): Values of bulk etch rate for new and stored heat treated PADC samples

\begin{tabular}{lllll}
\hline \multirow{2}{*}{$\begin{array}{l}\text { Storage } \\
\text { (years) }\end{array}$} & Time & \multicolumn{2}{c}{ Annealing Temperature $100^{\circ} \mathrm{C}$} & \multicolumn{2}{l}{ Annealing Temperature $200^{\circ} \mathrm{C}$} \\
\cline { 2 - 5 } & $\begin{array}{l}\text { Annealing } \\
1 \mathrm{~h}\end{array}$ & $\begin{array}{l}\text { Annealing } \\
8 \mathrm{~h}\end{array}$ & $\begin{array}{l}\text { Time } \\
\text { Annealing } \\
\text { 1h }\end{array}$ & $\begin{array}{l}\text { Time } \\
\text { Annealing Time 8h }\end{array}$ \\
\hline (fresh samples) & $1.2 \pm 0.06$ & $1.5 \pm 0.08$ & $3.3 \pm 0.17$ & $12.9 \pm 0.65$ \\
20 years ago & $1.1 \pm 0.06$ & $1.5 \pm 0.08$ & $4.5 \pm 0.23$ & $12.5 \pm 0.60$ \\
& & $1.55 \pm 0.09$ & $4.9 \pm 0.23$ & $13.5 \pm 0.68$ \\
30 years ago & $1.5 \pm 0.08$ & & & \\
\hline
\end{tabular}

Table (2): Values of bulk etch rate $(\mu \mathrm{m} / \mathrm{h})$ for fresh blank and stored blank heat treated PADC samples for annealing duration 1 hour

\begin{tabular}{|c|c|c|c|c|}
\hline \multirow{2}{*}{$\begin{array}{ll}\begin{array}{l}\text { Storage } \\
\text { (years) }\end{array} & \text { Time }\end{array}$} & \multicolumn{4}{|c|}{ Annealing Temperature } \\
\hline & $50^{\circ} \mathrm{C}$ & $100^{\circ} \mathrm{C}$ & $150^{\circ} \mathrm{C}$ & $200^{\circ} \mathrm{C}$ \\
\hline 0 (fresh sample) & $1 \pm 0.02$ & $1.2 \pm 0.06$ & $1.3 \pm 0.06$ & $3.3 \pm 0.17$ \\
\hline 20 years ago & $1.05 \pm 0.02$ & $1.1 \pm 0.03$ & $1.8 \pm 0.08$ & $4.5 \pm 0.23$ \\
\hline 30 years ago & $1 \pm 0.02$ & $1.5 \pm 0.08$ & $2.1 \pm 0.10$ & $4.9 \pm 0.23$ \\
\hline
\end{tabular}

Figure (2 a, b and c) show the induced improvement in the thermal stability of PADC (CR-39) polymeric material due to the annealing and the storage time. Figure (3) shows the effect of storage time on the thermal stability of polymeric material of fresh and stored PADC (CR-39) samples.

The activation energy was computed using the Dharwadkar and Kharkhanavala equation:

$$
\ln [-\ln (1-\alpha)]=\left(\frac{E_{a}}{R T_{i}^{2}}\right)\left(\frac{100}{T_{f}-T_{i}}\right) \theta+C
$$

where, $\alpha$, is a fraction of the polymer degraded at temperature $T$ under consideration

$$
\alpha=\frac{m_{s}-m}{m_{s}-m_{f}}
$$

where, $m_{s}, m$, and $m_{f}$ are the initial, actual and final mass of the sample, respectively; $E_{a}$, energy of activation; $R$, gas constant; $T_{i}$, temperature at inception of the reaction; $T_{f}$, temperature at completion of the reaction;

$$
\theta=T-T_{s}
$$

where, $T_{S}$, is the temperature at the point of inflection in the TG curve; $C$, constant. By plotting $\ln [-\ln (1-\alpha)]$ versus $\theta$, a straight line results from the slope, $\left(\frac{E}{R T_{i}^{2}}\right)\left(\frac{100}{T_{f}-T_{i}}\right) E_{a}$ can be calculated [23].

The values of activation energy determined for PADC fresh pristine and annealed fresh samples as well as the PADC pristine and annealed stored samples are listed in Table (3). There is an evident increase in the values of activation energy with increasing the annealing temperature for fresh and stored PADC samples. The increase in the activation energy of pristine and annealed fresh PADC samples agrees with the results of Jallinek, 1978 [21]. Such an increase may be attributed to changes in several factors, as the increase in packing density or an organized molecular arrangement, which induces the increase in the thermal stability of polymeric material [24].

Entropy of activation $(\Delta S, J / \mathrm{mol} / \mathrm{K})$ was computed from equation [25].

Intercept $=\log \frac{k R}{h \Phi E_{a}}+\frac{\Delta S}{2.303 R}$

where;

$\Delta \mathrm{S}$ : is the change in entropy, $\mathrm{E}_{\mathrm{a}}$ : is the activation energy from graph, $\mathrm{k}=1.38 \times 10^{-23} \mathrm{~J} / \mathrm{k}, \mathrm{R}=8.314$ $\mathrm{J} / \mathrm{k}$ mol, $\mathrm{h}=6.625 \times 10^{-34} \mathrm{~J} . \mathrm{s}$, and $\Phi=0.166$.

The calculated values of entropy of activation $\Delta S$ are illustrated in Table (3). The increase in the values of entropy of activation with the increase in the annealing temperature, again, supports the relative fast nature of reaction [24] and agrees with the results of Jallinek, 1978 [21]. 


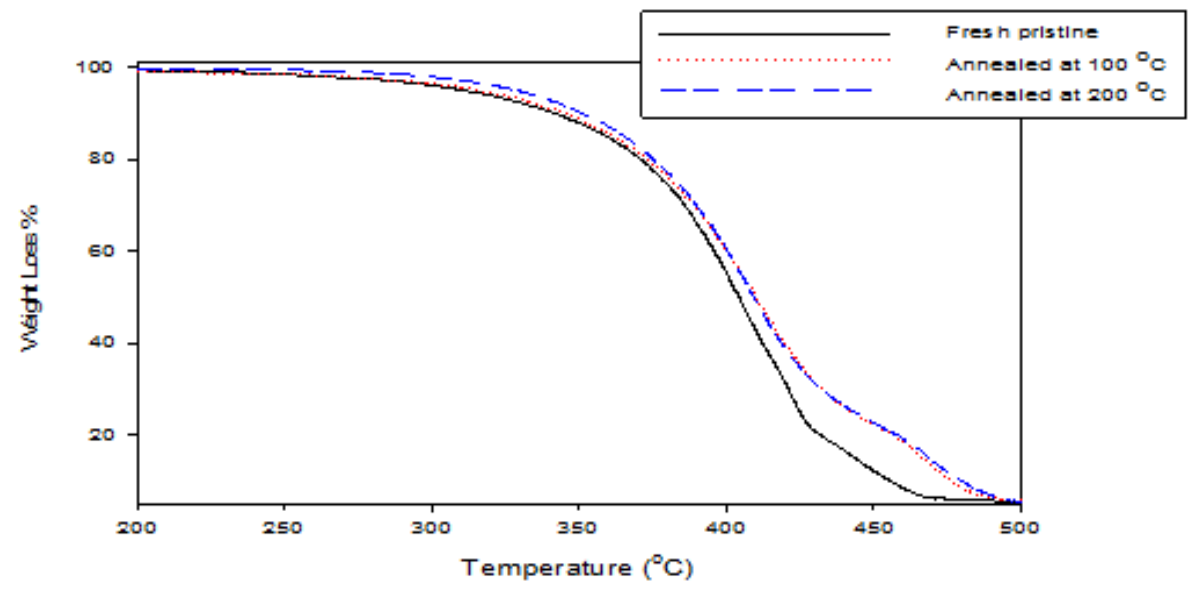

Figure (2.a): The rmogravimetric analysis for pristine and heated treatment fresh samples

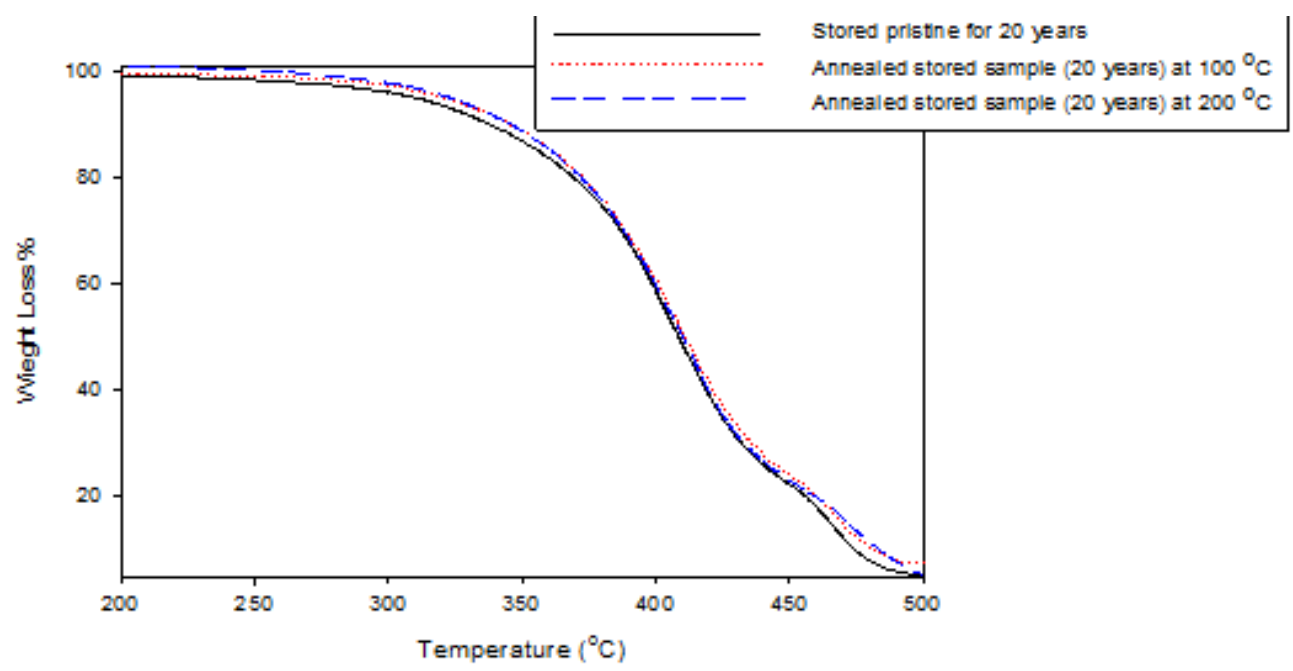

Figure (2.b): Thermogravimetric analysis for pristine and heated treatment stored samples for 20 years ago

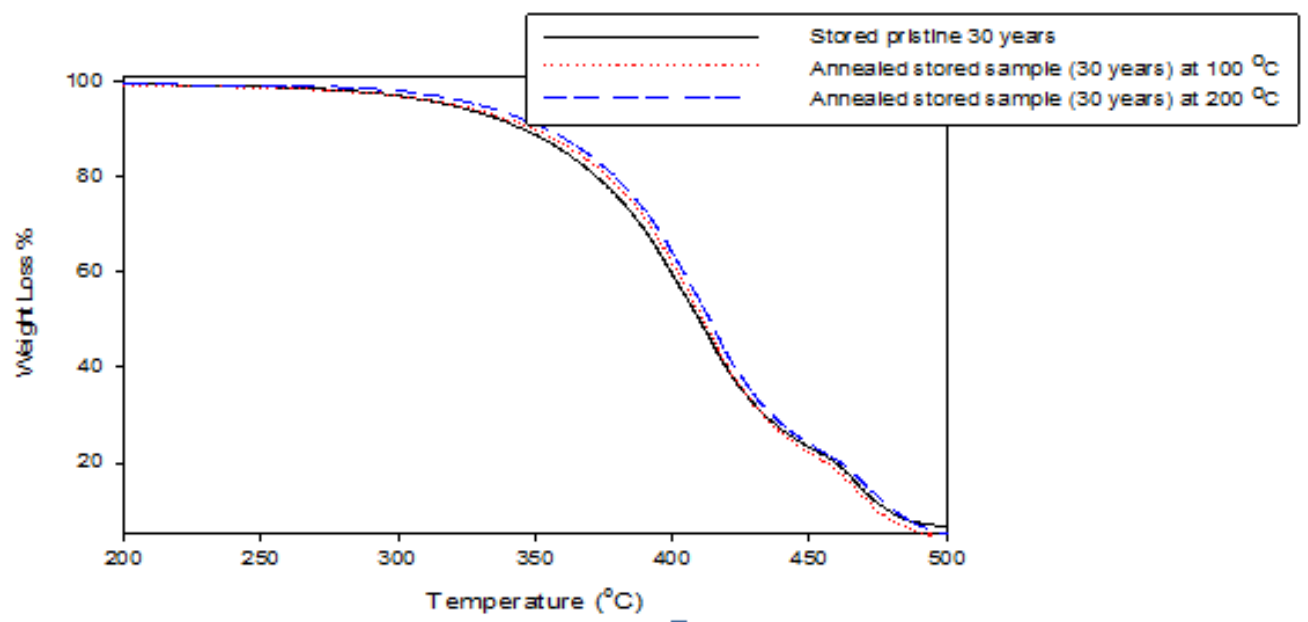

Figure (2.c): Thermogravimetric analysis for pristine and heated treatment samples stored for 30 years ago 


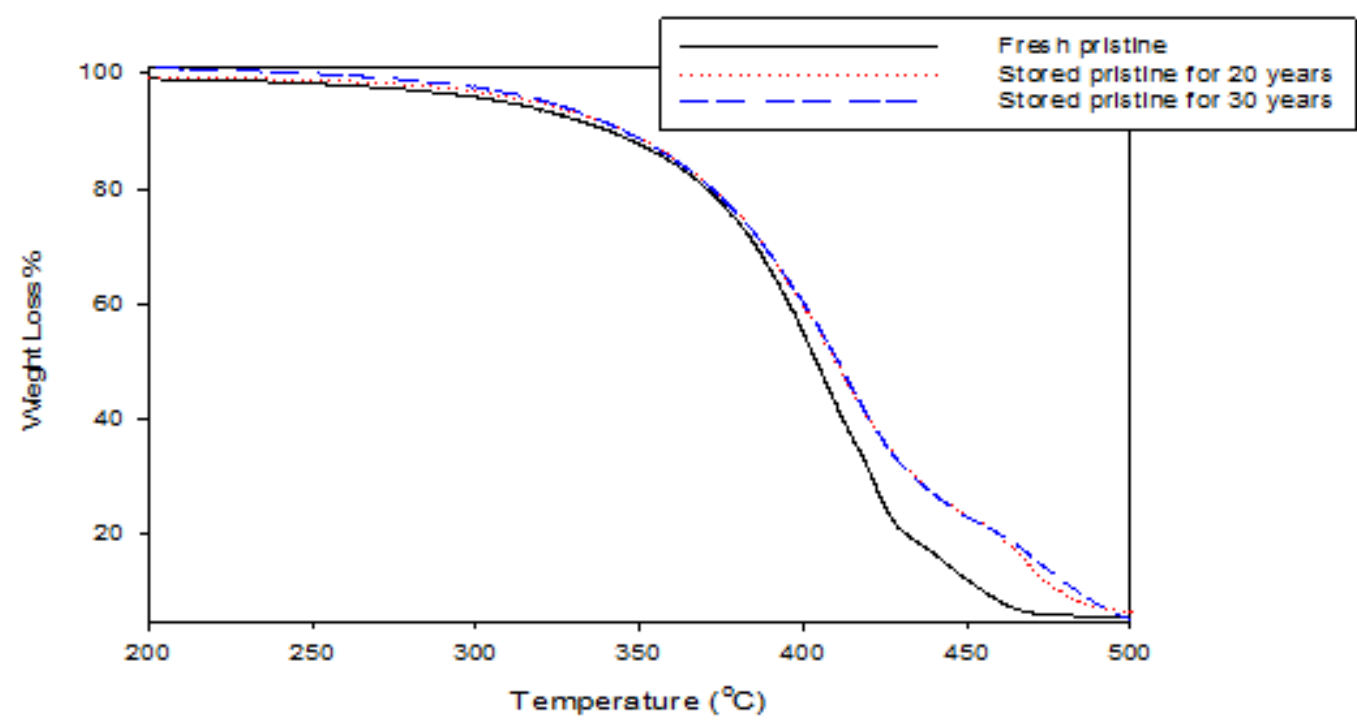

Figure (3): Thermogravimetric analysis for pristine fresh sample and pristine stored samples for 20 and 30 years ago

Table (3): The energy of activation and entropy of activation for fresh and stored heat treated PADC samples

\begin{tabular}{|c|c|c|}
\hline Sample & $\begin{array}{l}\text { The energy of activation }\left(\mathrm{E}_{\mathrm{a}} \mathrm{kJ}\right. \\
\left.\mathrm{mol}^{-1}\right)\end{array}$ & $\begin{array}{l}\text { The entropy of activation } \\
(\Delta \mathrm{S} \mathrm{J} / \mathrm{mol} / \mathrm{k})\end{array}$ \\
\hline Fresh pristine & 118.13 & -116.85 \\
\hline $\begin{array}{c}\text { Fresh sample } \\
\text { annealed at } 100{ }^{\circ} \mathrm{C}\end{array}$ & 141.26 & -114.43 \\
\hline $\begin{array}{c}\text { Fresh sample } \\
\text { annealed at } 200{ }^{\circ} \mathrm{C}\end{array}$ & 147.16 & -113.06 \\
\hline $\begin{array}{l}\text { Stored sample for } \\
20 \text { years pristine }\end{array}$ & 140.61 & -114.26 \\
\hline $\begin{array}{l}\text { Stored sample for } \\
20 \text { years annealed } \\
\text { at } 100^{\circ} \mathrm{C}\end{array}$ & 143.53 & -113.92 \\
\hline $\begin{array}{l}\text { Stored sample for } \\
20 \text { years annealed } \\
\text { at } 200^{\circ} \mathrm{C}\end{array}$ & 149.65 & -112.30 \\
\hline $\begin{array}{l}\text { Stored sample for } \\
30 \text { years pristine }\end{array}$ & 150.36 & -113.46 \\
\hline $\begin{array}{c}\text { Stored sample for } \\
30 \text { years annealed } \\
\text { at } 100{ }^{\circ} \mathrm{C}\end{array}$ & 152.89 & -113.11 \\
\hline $\begin{array}{c}\text { Stored sample for } \\
30 \text { years annealed } \\
\text { at } 200^{\circ} \mathrm{C}\end{array}$ & 161.20 & -111.81 \\
\hline
\end{tabular}


The X-ray diffraction of both the pristine sample and the stored samples was carried out. Figure (4) illustrates that there is no change in the structure of stored PADC (CR-39) polymeric material. Figures ( $5 \mathbf{a}, \mathbf{b}$ and c) clarify that there is no change in the structure of annealed PADC (CR-39) polymeric material.

Figures ( $5 \mathbf{a}, \mathbf{b}$ and $\mathbf{c})$ illustrate the change in the degree of crystallinity percentage for annealed, fresh and stored, PADC samples. Table (4) shows the change of the degree of crystallinity percentage for annealed PADC, fresh and stored, samples. The degree of crystallinity $\mathrm{Xc}$ is obtained from the equation [26]:

Where:

$x_{c}=\frac{A_{c}}{A}$
, and $A=A_{c}+A_{a}$

where $A$ : is the area of the specimen, $A_{c}$ and $A_{a}$ : are the areas of crystalline and amorphous material in the sample, respectively.

Table (4) shows that the percentage change of the degree of crystallinity for annealed PADC, fresh and stored, samples at $200^{\circ} \mathrm{C}$ is greater than the percentage change that occurred at $100^{\circ} \mathrm{C}$. On the other hand, it is well known that CR-39 is a partly crystalline polymer with a dominant amorphous phase. Thus, it could be noticed that the change in the degree of crystallinity is a percentage with respect to the degree of crystallinity (minor phase) in the pristine. The induced changes in the degree of crystallinity percentage may be due to the degradation of the crystalline structure in the polymeric material [27].

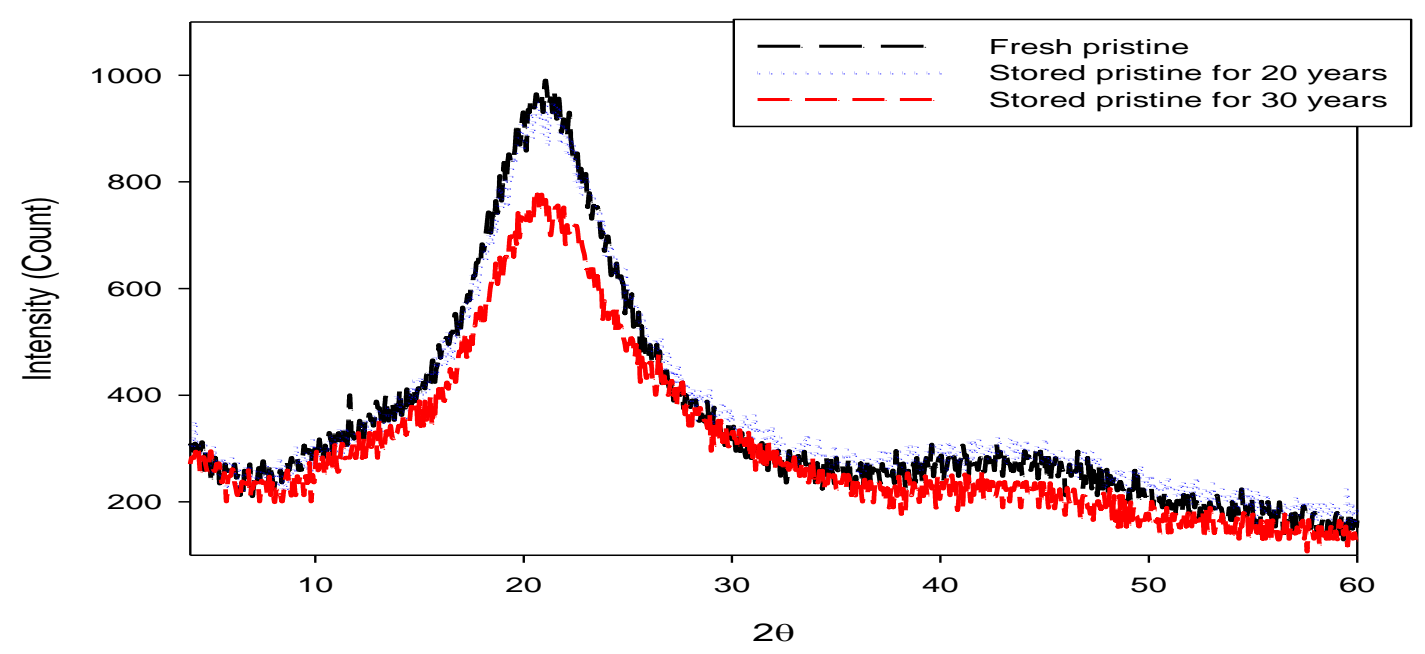

Figure (4): The X-ray diffraction spectrum of pristine fresh and stored samples 


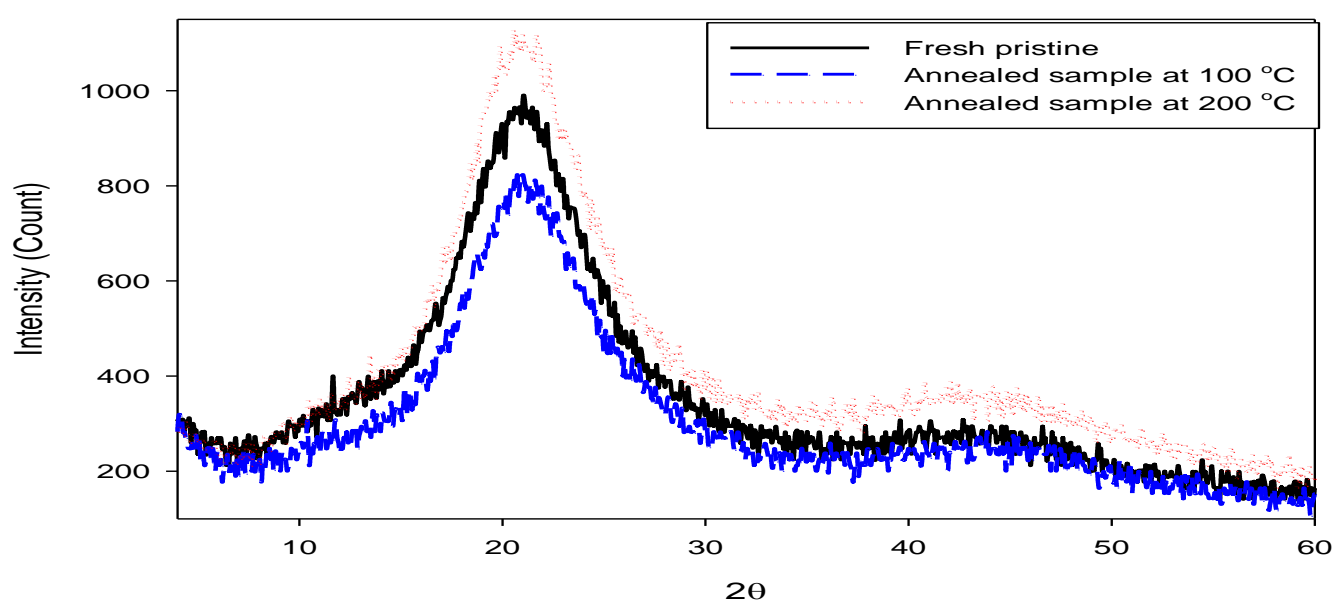

Fig. (5.a): The X-ray diffraction spectrum of pristine and annealed fresh samples

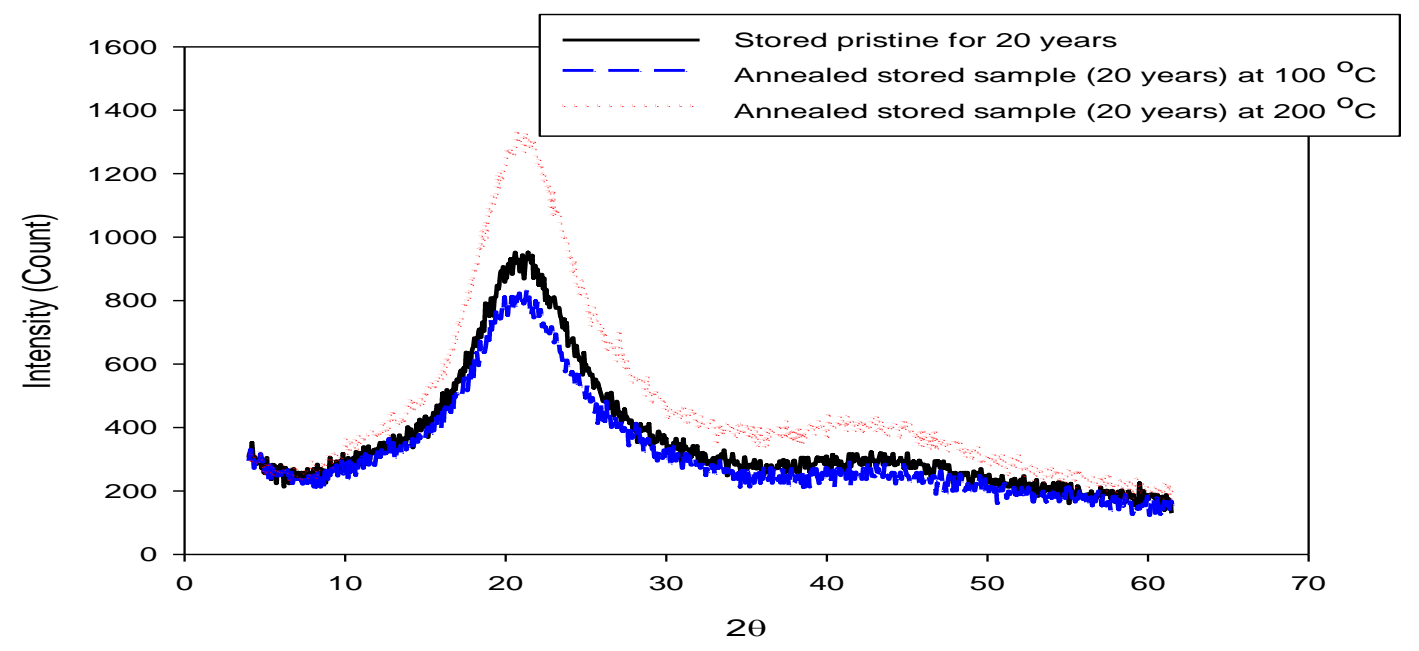

Fig. (5.b): The X-ray diffraction spectrum of stored sample for 20 years and annealed samples 


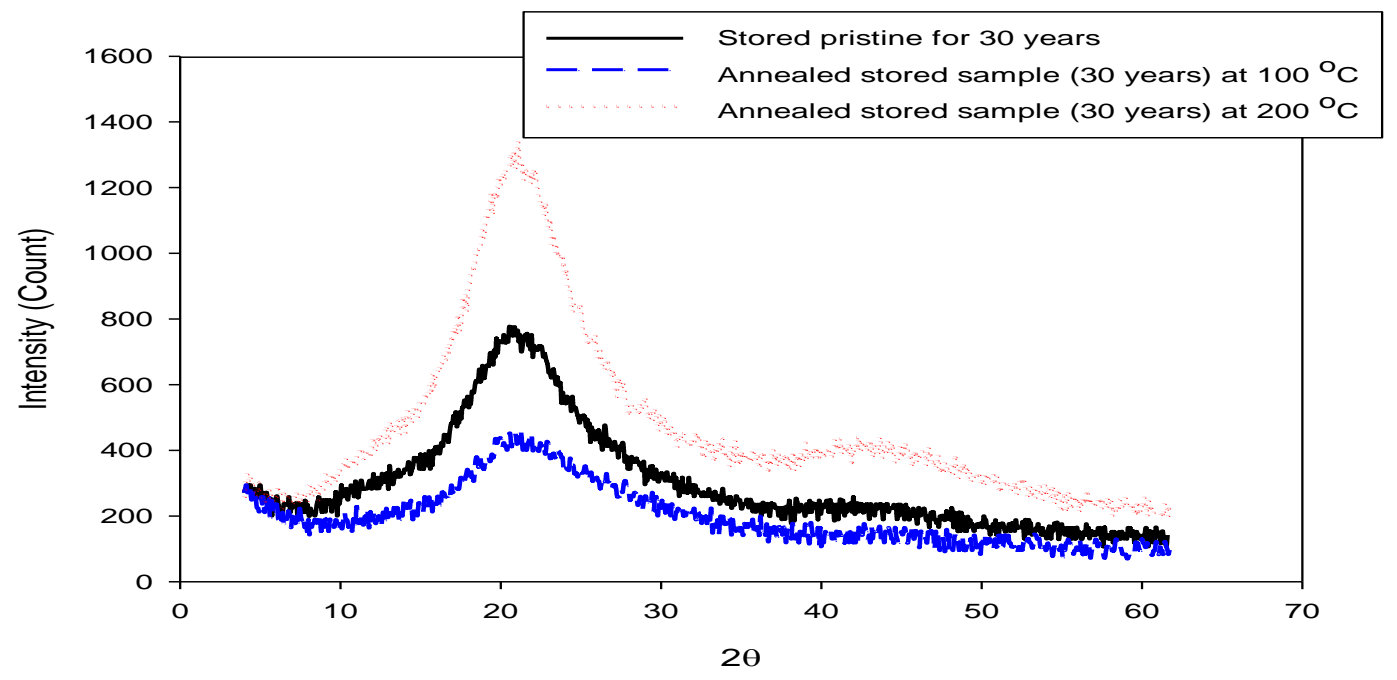

Fig. (5.c): The X-ray diffraction spectrum of stored sample for 30 years and annealed samples.

Table (4): Values of the degree of crystallinity percentage for PADC annealed fresh and stored samples.

\begin{tabular}{|c|c|}
\hline Sample & The degree of crystallinity (\%) \\
\hline $\begin{array}{c}\text { Fresh sample annealed at } 100 \\
{ }^{\circ} \mathbf{C}\end{array}$ & 45.57 \\
\hline $\begin{array}{c}\text { Fresh sample annealed at } 200 \\
{ }^{\circ} \mathrm{C}\end{array}$ & 53.52 \\
\hline $\begin{array}{l}\text { Stored sample for } 20 \text { years } \\
\text { annealed at } 100^{\circ} \mathrm{C}\end{array}$ & 46.66 \\
\hline $\begin{array}{l}\text { Stored sample for } 20 \text { years } \\
\text { annealed at } 200^{\circ} \mathrm{C}\end{array}$ & 58.38 \\
\hline $\begin{array}{l}\text { Stored sample for } 30 \text { years } \\
\text { annealed at } 100{ }^{\circ} \mathrm{C}\end{array}$ & 36.94 \\
\hline $\begin{array}{l}\text { Stored sample for } 30 \text { years } \\
\text { annealed at } 200{ }^{\circ} \mathrm{C}\end{array}$ & 62.77 \\
\hline
\end{tabular}

FTIR spectra of fresh CR-39 and stored samples for 20 and 30 years as well as the thermal annealing samples are represented in Figures 6 (a), (b), (c) and (d) measured using (Jasco FT-IR 460 Pulse). The spectra show the appearance of sharp bands at $2924 \mathrm{~cm}^{-1}, 1743$ $\mathrm{cm}^{-1}$ and 1021 or $1020 \mathrm{~cm}^{-1}$ due to $-\mathrm{CH}_{2}$ stretching, $\mathrm{C}=\mathrm{O}$ and $-\mathrm{C}-\mathrm{O}-\mathrm{C}-$ groups respectively. Whereas, other strong bands at 1459, 1460 and $1399 \mathrm{~cm}^{-1}$ can be attributed to the $\mathrm{C}-\mathrm{H}$ bending and $1264 \mathrm{~cm}^{-1}$ for $\mathrm{C}-\mathrm{O}$. The other small bands $\sim 1646 \mathrm{~cm}^{-1}$ for $\mathrm{C}=\mathrm{C}$ and the band at $786 \mathrm{~cm}^{-1}$ are out of the $\mathrm{C}-\mathrm{H}$ plan bending. The spectra confirm that the structure of the fresh, stored and annealing samples did not change. 


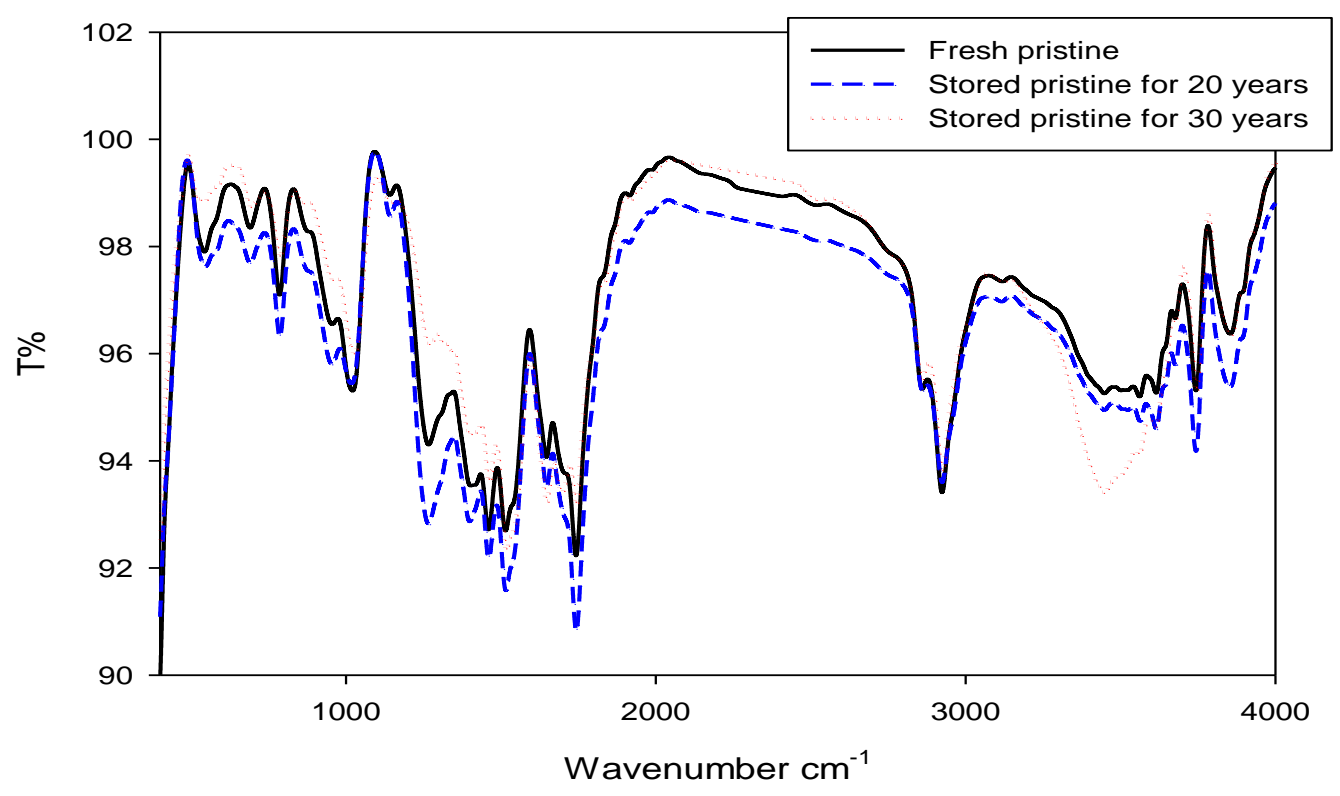

Fig. (6.a): FTIR spectrum of fresh pristine and stored pristine for ( 20 and 30) years

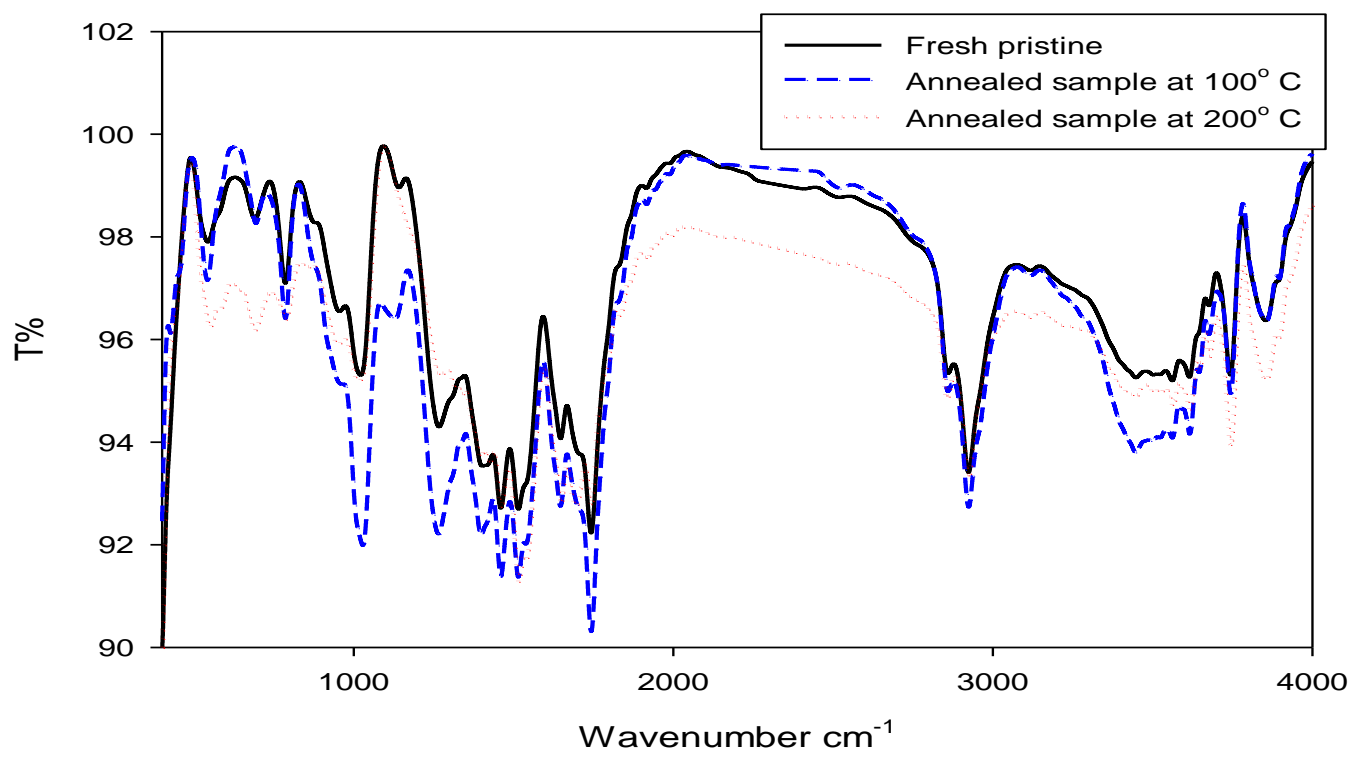

Fig. (6.b): FTIR spectrum of fresh pristine and annealed fresh samples at 100 and $200^{\circ} \mathrm{C}$

Corresponding author: drmarwashoeib@hotmail.com

DOI: $10.21608 / a j n s a .2018 .2917 .1058$

(C) Scientific Information, Documentation and Publishing Office (SIDPO)-EAEA 


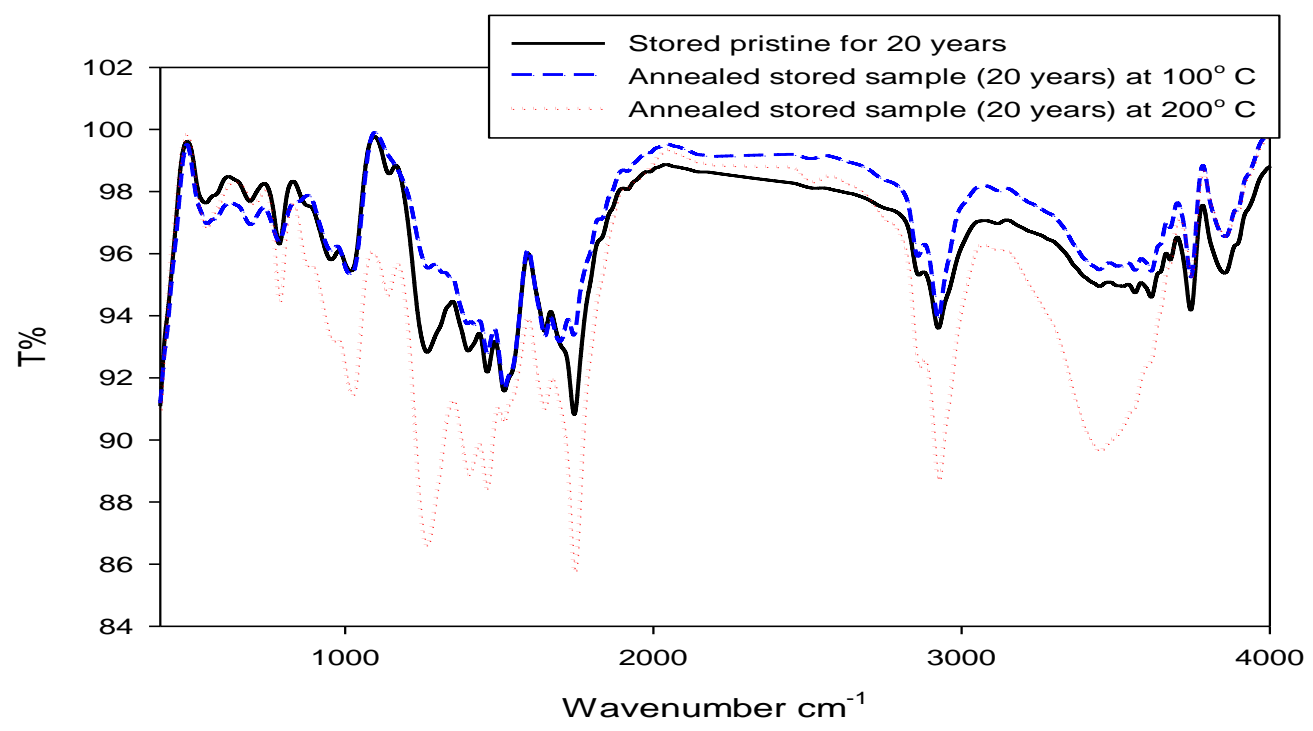

Figure (6.c): FTIR spectrum of stored pristine for 20 years and annealed stored samples at 100 and $200^{\circ} \mathrm{C}$

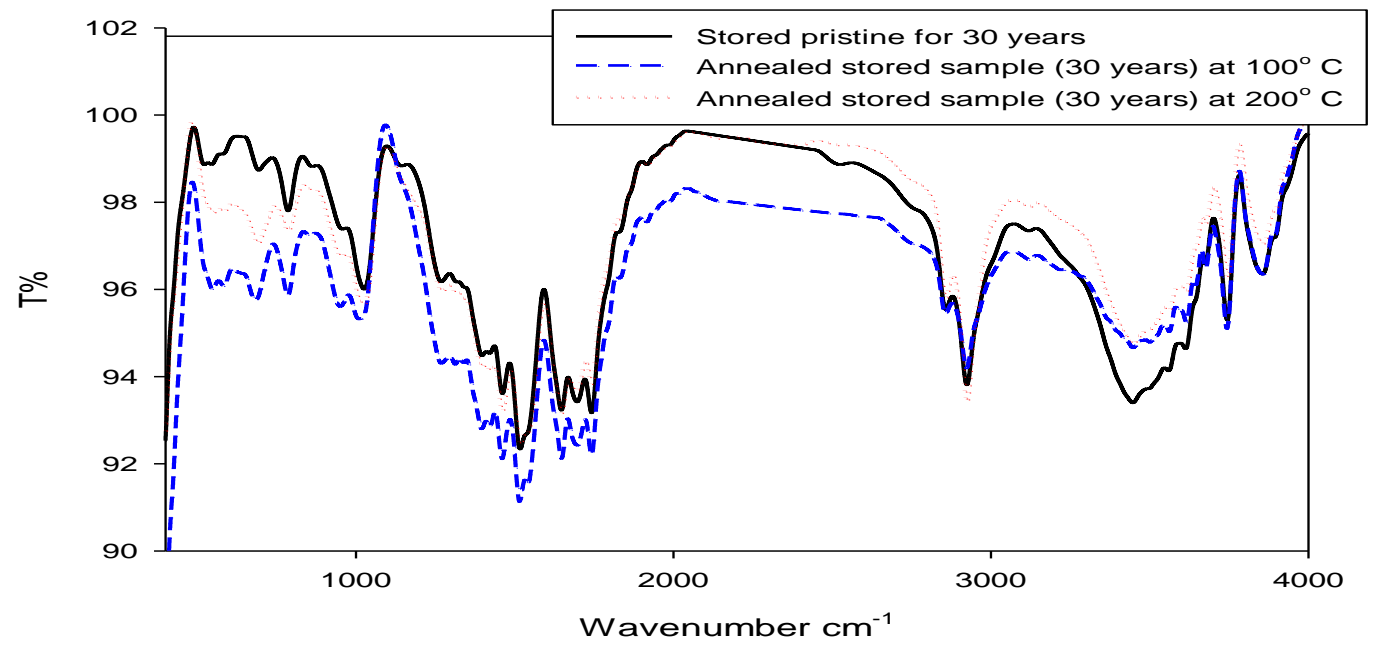

Fig. (6.d): FTIR spectrum of stored pristine for 30 years and annealed stored samples at 100 and $200^{\circ} \mathrm{C}$

\section{Conclusion}

The bulk etch rate values of PADC (CR-39) do not depend on the storage time. On the other hand, the bulk etch rates increase with increasing of the annealing temperature and annealing time. This might be due to the thermal degradation in polymeric material. The increase in the activation energies for thermal degradation and the entropy of activation with the increase in heating temperature clearly indicates the enhancement in thermal stability of PADC (CR-39) as an effect of heat treatment. Thus, it can be concluded that the thermal stability of PADC (CR-39) can possibly be improved as per requirement through heat Arab J. Nucl. Sci. \& Applic. Vol. 52, No. 1 (2019) treatment. The increase in the activation energies for thermal degradation and the entropy of activation, when storage time increases, clearly indicates the slight increment in thermal stability of PADC (CR-39) as an effect of storage time. The induced changes in the degree of crystallinity percentage of annealed, fresh and stored, PADC samples may be due to the degradation of the crystalline structure in the polymeric material.

\section{Acknowledgement}

The authors are grateful to Prof. Dr. Essam Kishar at Women's College, Ain Shams University for his continuous encouragement and support. 


\section{References}

1.Durrani, S.A. and Bull, R.K. (1987) Solid State Nuclear Track Detection Principles, Methods and Appli., Pergamon Press, UK.

2. Nur Sha'dah, Z., Iskandar, S.M., Azhar, A.R., Suuhaimi, M.J., Nur Lina and Halimah, M.K. (2014) UV-VIS Spectral Evaluation of CR-39 Detector Exposed with Diagnostic Dosage, Sains Malaysiana, 43, 953-958.

3. Abdul- Kader, El- Badry, B.A., Zaki, M.F., Hegazy, T.M. and Hashem, H.M. (2010) Ion Beam Modification of Surface Properties of CR-39, Philosophical Magazine, 90, 2543-2555.

4.El- Shahawy, M.A. (1997) Spectral Changes of CR39 Induced by Irradiation and Heat Treatment, Polymer Degradation and Stability, 57, 157-161.

5. Fleischer, R.L., Price, P.B. and Walker, R.M. (1975) Nuclear Tracks in Solids, Principles and Applications, University of California Press, Berkeley, USA.

6.Jaspal, S., Surinder, S. and Virk, H. S. (1988) Fission Track Dating of some Copper Ore Formations in India, Nucl. Tracks Radiat. Meas., 15(1/4), 187-190.

7. Yamauchi, T. (2003) Studies on the Nuclear Tracks in CR- 39 Plastic, J. Radiat. Meas., 36, 73- 80.

8. Adams, J.H. (1981) In: Proceedings of 11th Int. Conf. Solid State Nuclear Track Detectors, Bristol, 145148.

9. Tager, A. (1978) Physical Chemistry of Polymer, 2nd ed. Mir Publishers, Moscow.

10. Rana, A.M., Qureshi, I.E., Khan, E.U. , S. Manzoor, S., Shahzad, M. I. and Khan, H.A. (2000) Thermal Annealing of Fission Fragment Radiation Damage in CR-39, Nucl. Instrum. Meth. Phys. Res., 170, 149-155.

11. Harwey, J.R. and Weeks, A.R.A. (1986) Neutron Dosimetry System Based on the Chemical Etch of CR-39, Nucl. Tracks, 12, 629.

12. Portwood, T., Henshaw, D.L. and Stejny, J. (1986) Ageing Effects in CR-39, Nucl. Tracks, 12, 109.

13.Morawetz, H. (1960) Trapped Radicals in High Polymer Systems in Formation and Trapping of Free Radicals, Academic Press, New York\& London.

14. Kuleznev, V.N. and Shershnev, V.A. (1990) The Chemistry and Physics of Polymers, Printed in the Union Soviet Socialist Republics.
15.Dipak Sinha, I.C. and Tokavi ,Toka Swu (2012) Effect of Gamma Radiation on Thermal Stability of PADC-American Acrylics Detector, Advances Appl. Sci. Res., 3, 2128-2133.

16.Hajra Choudhury, S.K. (1999) Materials Science and Processes, 2nd ed., Indian Book Distributing Co..

17.Malik, F., Khan, E.U., Qureshi, I.E., Husaini, S.N., Sajid, M., Karim, S. and Jamil, K. (2002) Swelling in CR-39 and its Effect on Bulk Etch Rate, Radiat. Meas., 35, 301-305.

18. Abou El-Khier, A.A., Gaber, M., Mahmoud, S.A. and EL-Shafey, E. (1995) The Effect of Environmental Treatment on the Track Response of the CR-39 Plastic Detector, Material Latters, 24, 41.

19.Pinheiro Filho, J.D., Dasilva, A.X. and Santos, R.C. (1996) Studies of Isochronal and Isothermal Annealing of Alpha Particle Tracks in CR-39 Polymer Detectors, Nucl. Instr. Meth. Phys. Res., 111, 104.

20. Shoeib, M.Y., Hegazy, T.M. and Hassan, G.M. (2014) Effect of Heat Treatment on Some Properties of CR- 39 Nuclear Track Detector Irradiated by Gamma Ray, BJBAS, 3, 74-75.

21.Jellinek, H.H.G. (1978) Aspects of Degradation and Stabilization of Polymers, Elsevier Scientific Publishing Company, New York.

22. Renu Gupta, Kumar, V., Goyal, P.K. and Shyam Kumar (2010) Thermogravimetric Analysis of Heat Treated CR-39 Polymer, J. Chem. Pharm. Res., 2, 629- 634.

23. Dharwadkar, S.R. and Kharkhanavala, M.D. (1969) Thermal Analysis, Academic Press, New York.

24. Anslyn, E.V. and Dougherty, D.A. (2006) Modern Physical Organic Chemistry, Edwards Brothers, Inc., USA.

25.Phadneis, A. B. and Deshpande, V.V. (1983) Determination of the Kinetics and Mechanism of a Solid State Reaction, Thermo Chimica Acta, 62, 361367.

26. Young, R.J. and Lovell, P.A. (1991) Introduction to Polymers. $2^{\text {nd }}$ ed, Chapman and Hall, London.

27.Fried, J. R. (2005) Polymer Science and Technology, 2nd ed, Prentice Hall of India New Delhi. 